\title{
Modos de viver, narrar e guardar: diálogos cruzados sobre pesquisa (auto)biográfica
}

\begin{abstract}
Resumo
O texto centra-se num inventário das produções circunscritas na sexta edição do CIPA, em particular, os livros publicados na Coleção 'Artes de viver, narrar e guardar', que compreendeu sete eixos temáticos: Pesquisa, fontes e questões, Espaços formativos, memórias e narrativas, Narrativas digitais, memórias e guarda, Infância, aprendizagem e exercício da escrita, (Auto)biografia, literatura e história, Escrita de si, resistência e empoderamento e Histórias de vida, gênero e educação. Busca-se, assim, visibilizar modos de produção no campo da pesquisa (auto)biográfica no Brasil, com destaques para apreensões de novos contornos, avanços e configurações que tais estudos têm assumido numa rede de pesquisa nacional e internacional, entre grupos de pesquisas, associações e investigadores de diferentes campos disciplinares.
\end{abstract}

Palavras-chave: Pesquisa (auto)biográfica; Narrativas e guarda; Redes de pesquisa.

\author{
Ana Chrystina Mignot \\ Doutora em Educação pela \\ Pontifícia Universidade Católica \\ do rio de Janeiro - PUC/RJ - \\ Brasil \\ acmignot@terra.com.br

\section{Elizeu Clementino de Souza} \\ Doutor em Educação pela \\ Universidade Federal da Bahia - \\ UFBA - Brasil \\ esclementino@uol.com.br
}

\section{Para citar este artigo:}

MIGNOT, Ana Chrystina; SOUZA, Elizeu Clementino de. Modos de viver, narrar e guardar: diálogos cruzados sobre pesquisa (auto)biográfica. Revista Linhas. Florianópolis, v. 16, n. 32, p. 10 - 33, set./dez. 2015.

\section{DOI: $10.5965 / 1984723816322015010$}

http://dx.doi.org/10.5965/1984723816322015010 


\title{
Modes of living, narrating and keeping: crossed dialogues on (auto) biographical research
}

\begin{abstract}
The text focuses on an overview of circumscribed productions in the sixth edition of CIPA, in particular, the books published in the Collection "Arts of living, narrating and keeping", which included seven themes: Research, sources and issues, Spaces of formation, memories and narratives, Digital narratives, memories and guard, Childhood, learning and writing exercise, (Auto)biography, literature and history, Self-writing, strength and empowerment and Stories of life, gender and education. Thus, the aim is to visualize production methods in the field of (Auto) biographical research in Brazil, with emphasis on seizures of new contours, advances and settings that such studies have taken on a national and international research network among research groups, associations and researchers from different disciplines.
\end{abstract}

Keywords: (Auto) biographical research; Narratives and guard; Research networks. 


\section{Diálogos iniciais sobre o campo (auto)biográfico}

Seguindo as pistas deixadas por Souza, Sousa e Catani (2008), quando examinaram as produções das duas primeiras edições do Congresso Internacional de Pesquisa (Auto)Biográfica (CIPA), observamos que este evento científico imprime, desde a sua primeira edição, o propósito de sistematizar "experiências com pesquisas que discutem dimensões ligadas às histórias de vida, memória, narrativas e às (auto)biografias como práticas de formação e investigação" (SOUZA; SOUSA; CATANI, 2008, p. 35), proporcionando mapear as produções do campo de pesquisa, "as possíveis entradas, tipos de relatos, formas como os sujeitos professores, alunos, pesquisadores e outros contam, narram suas histórias e como os relatos possibilitam apreender saberes e conhecimento dessas experiências" (SOUZA; SOUSA; CATANI, p. 35).

O presente texto se inscreve no mesmo esforço já empreendido de mapeamento ou do que se convencionou chamar de "estado da arte", que busca visibilizar modos de produção no campo da pesquisa (auto)biográfica no Brasil, com destaques para apreensões de novos contornos, avanços e configurações que tais estudos têm assumido numa rede de pesquisa nacional e internacional, entre grupos de pesquisas, associações e investigadores de diferentes campos disciplinares. ${ }^{1}$ Assim, com o objetivo de inventariar as temáticas recorrentes, as novas inflexões teóricas e metodológicas e as redes de pesquisa que se fazem representar no campo (auto)biográfico, este texto elege a coleção Modos de viver, narrar e guardar ${ }^{2}$ no conjuntos das produções do VI CIPA, realizado na Universidade do Rio de Janeiro, em novembro de 2014, em parceria com a Associação Brasileira de Pesquisa (Auto)Biográfica.

Em outras palavras, pretendemos ampliar o inventário sobre as produções do VI CIPA, a partir da sistematização de algumas questões relacionadas às disposições teórico-

\footnotetext{
1 Outros inventários sobre as edições do Congresso Internacional de Pesquisa (Auto)Biográfica podem ser vistos no livro Pesquisa (Auto)Biográfica, fontes e questões, organizado por Maria Helena Menna Barreto Abrahão, Inês Ferreira de Souza Bragança e Mairce da Silva Araújo, na Coleção Modos de Viver, Narrar e Guardar, que será comentada ao final deste texto.

2 A Coleção Modos de viver, narrar e guardar, dirigida por Ana Chrystina Mignot e Elizeu Clementino de Souza e editada com o apoio do CNPq, CAPES, FAPERJ, Fundação Cesgranrio, UNIMEd/Rio de Janeiro e BIOgraph, foi publicada pela Editora CRV.
} 
metodológicas que favoreceram a publicação desta coleção de livros, ${ }^{3}$ configurando-se como mais um bom exemplo que evidencia esta convergência: o crescimento vertical do campo da pesquisa (auto)biográfica, entendido como elevação substantiva e crescente dos níveis de qualidade da produção e a expansão horizontal, significando o alargamento do território ocupado por pessoas e instituições envolvidas com esse tipo de pesquisa (individual ou em colaboração), no Brasil e em nossas conexões fora dele.

Para tanto, na arquitetura do texto, privilegiaremos, inicialmente, uma leitura do VI CIPA, dos eixos temáticos que deram forma e foco ao congresso, para depois nos debruçarmos sobre a coleção como um todo e em cada volume em particular.

\section{CIPA: esboço de uma cartografia sobre a pesquisa (auto)biográfica}

Para traçar uma cartografia da potente produção resultante do VI CIPA, é importante ressaltar o congresso como um espaço acadêmico, científico e existencial, promotor de partilhas, reflexões e aprofundamento da produção de conhecimento e como uma real oportunidade para a ampliação das discussões na área e de contribuições relevantes para os domínio da pesquisa (auto)biográfica em rede, o que se expressou em sua programação.

Com o tema - Entre o público e o privado: modos de viver, narrar e guardar contemplou as mais diversas vertentes de pesquisa (auto)biográfica e contribuiu, mais uma vez, para estreitar laços institucionais e entre grupos de pesquisa brasileiros e estrangeiros de diferentes tradições disciplinares com vistas ao avanço desse campo de pesquisa. O tema proposto possibilitou o fortalecimento das parcerias institucionais e a internacionalização das pesquisas realizadas no país sobre o biográfico e o autobiográfico

\footnotetext{
3 A coleção Modos de viver, narrar e guardar conta com sete volumes: Pesquisa (auto)biográfica, fontes e questões, organizado por Maria Helena Menna Barreto Abrahão, Inês Ferreira de Souza Bragança e Mairce da Silva Araújo; Espaços formativos, memórias e narrativas, organizado por Helena Amaral Fontoura, Isabel Alice Oswald Monteiro Lelis e Iduina Mont'Alverne Chaves; Narrativas digitais, memórias e guarda, organizado por Maria Luiza Magalhães Bastos Oswald e Dilton Ribeiro do Couto Junior; Infância, aprendizagem e exercício da escrita, organizado por Ana Chrystina Mignot, Carmen Sanches Sampaio e Maria da Conceição Passeggi; Auto(biografia), literatura e história, organizado por Maria Celi Chaves Vasconcelos, Verbena Maria Rocha Cordeiro e Paula Perin Vicentini; Escrita de si, resistência e empoderamento, organizado por Elizeu Clementino de Souza, Ana Luiza Grillo Balassiano e Anne-Marie Milon Oliveira; Histórias de vida, gênero e educação, organizado por Lia Faria, Yolanda Lima Lobo e Patrícia Coelho.
} 
como domínio de pesquisa que tem se consolidado a cada ano nos estudos pósgraduados com foco na pesquisa educacional, nas práticas de formação e questões relacionadas à memória e à guarda do escrito.

Além da ampla programação acadêmica ${ }^{4}$, com conferências, mesas redondas, simpósios, sessões de conversas, sessões de comunicações e pôsteres, bem como conversas com autores, realizados por pesquisadores de reconhecida produção científica do Brasil, Argentina, Colômbia, Peru, México, Bélgica, França, Itália, Espanha, Portugal e Porto Rico, o VI CIPA teve uma extensa programação cultural, com exposições abertas à visitação pública, com a curadoria de críticos literários, historiadores da arte, historiadores da educação e pesquisadores de formações diversas, em diferentes espaços culturais da Universidade do Estado do Rio de Janeiro e da cidade, incluindo a Biblioteca da Mangueira e o Centro Cultural Banco do Brasil, permitindo que ciência e arte, se cruzassem e se complementassem, nas exposições, café biográfico e mostra de cinema. ${ }^{5}$

O VI CIPA congregou não apenas professores universitários, mas também estudantes da pós-graduação e da graduação, assim como professores da escola básica e

\begin{abstract}
4 Cabe aqui destacar a Conferência da abertura realizada por Beatrice Barbalato (Louvain - Bélgica), a Conferência de encerramento, proferida por Antonio Castillo Gomes (Alcalá - Espanha), bem como as seguintes mesas redondas: 1. Pesquisa (auto)biográfica, fontes e questões: Inês Bragança (UERJ/Brasil); Maria Helena Menna Barreto Abrahão (PUC-RGS /Brasil); Denice Barbara Catani (USP/Brasil) e José Miguel Marinas (Complutense de Madrid/Espanha); 2. Espaços formativos, memórias e narrativas: Helena Fontoura (UERJ/Brasil); Caterina Benelli (Studi di Messina /Itália); Gabriel Jaime Murilo Arango (Antioquia/Colômbia); Daniel Suárez (UBA/Argentina); 3. Narrativas digitais, memórias e guarda: Paula Sibília (UFF/Brasil); Karen Worcman (Museu da Pessoa/Brasil); Daniel Escandiel Montiel (Salamanca/Espanha); Leonor Arfuch (UBA/Argentina); 4. Infância, aprendizagem e exercício da escrita: Maria da Conceição Passeggi (UFRN/Brasil); Juri Meda (Universitá di Macerata/Italia); Maria Helena Bastos (PUC-RS/Brasil); Verónica Sierra Blás (Alcalá/Espanha); 5. (Auto)biografia, literatura e história: Maria Celi Vasconcelos (UCP/UERJ/Brasil); Paulo Rezzutti (IHGB/São Paulo/Brasil); Paula Vicentini (USP/Brasil); Eneida Maria Souza (UFMG/Brasil); 6. Escrita de si, resistência e empoderamento: Anne-Marie Millon (UERJ/Brasil); Elizeu Clementino de Souza (UNEB/Brasil); Christine Delory-Momberger (Paris 13/França); Christophe Newiadomski (Lille 3/França); 7. Histórias de vida, gênero e educação: Lia Faria (UERJ/Brasil); Sara Beatriz Guardia (San Martin de Porres/Peru); Oresta Lopez (San Luis/México); Tania Dauster (PUC-Rio/Brasil).
\end{abstract}

5 "O olhar: retorno de um sociólogo ao espaço das periferias romanas", "Histórias bordadas", "Eu/outro/eu", "Devir-Cidade: Histórias de vida - fotografias de Mangueira" e "Condessa de Barral: cartas e imagens"; na premiadíssima peça de teatro "O filho eterno" que aborda a construção do amor paterno por um jovem escritor que, na maternidade, em meio às expectativas do nascimento, é informado pelos médicos que seu filho nasceu com síndrome de Down; no Café Biográfico que debate com escritores e historiadores duas das dimensões mais visíveis da presente politização do debate sobre biografias - a questão da eliminação de mecanismos legais cerceadores da liberdade de expressão no campo das publicações de biografias e a recuperação e aprofundamento da memória/história do regime militar brasileiro através das biografias de seus protagonistas; ou na Mostra de Cinema que tematiza o (auto)biográfico. 
integrantes de movimentos sociais, e contou com uma Comissão Organizadora ${ }^{6}$ e uma Comissão Científica compostas por representantes de diversas instituições e grupos de pesquisa brasileiros e de outros países: Argentina, Colômbia, Dinamarca, Espanha, França, Itália, México, Peru, Porto Rico, Portugal e Suíça, conforme se pode constatar na composição das Comissões Organizadora e Científica.

Organizado em torno de eixos temáticos - Pesquisa (auto)biográfica, fontes e questões; Espaços formativos, memórias e narrativas; Infância, aprendizagem e exercício da escrita; Narrativas digitais, memórias e guarda; (Auto)biografia, literatura e história; Escrita de si, resistência e empoderamento; Histórias de vida, gênero e educação - teve trabalhos que expressam a valorização das subjetividades, dos processos memorialísticos, das histórias de vida e autobiografias, com abordagens mais frequentes em práticas de formação e em história da educação. Um breve exame dos eixos temáticos e dos trabalhos apresentados têm, com frequência, inspirado a proposição de investigações e modalidades de intervenção prática.

A aposta nos simpósios, com a presença de pesquisadores de, no mínimo, dois países diferentes, em especial, demonstrou ser um acerto. Tal exigência não inibiu a proposição de 21 sessões com pesquisadores que têm projetos comuns de modo embrionário ou mais consolidados, ampliando uma rede de pesquisa e formação centrada na vertente dos estudos (auto)biográficos. Ao todo, foram propostos e aprovados 21 simpósios, coordenados por pesquisadores brasileiros vinculados a Programas de PósGraduação em Educação de várias regiões do país, tais como Universidade do Estado de Santa Catarina, Universidade Federal de Mato Grosso, Universidade do Estado do Rio de Janeiro, Universidade de São Paulo, Universidade Federal do Estado do Rio de Janeiro, Pontifícia Universidade Católica do Rio de Janeiro, Universidade do Estado da Bahia, Universidade Federal do Rio Grande do Sul, por exemplo. A acolhida a esta proposta, pioneira no âmbito dos eventos da Associação Brasileira de Pesquisa (Auto)biográfica

\footnotetext{
6 Cabe aqui destacar que a Comissão Organizadora Local, por sua vez, contou com a presença de representantes de Programas de Pós-Graduação em Educação de diversas instituições do Rio de Janeiro Universidade Federal Fluminense (UFF), Universidade Federal do Estado do Rio de Janeiro (UNIRIO), Universidade Estadual do Norte Fluminense Darcy Ribeiro (UENF), Pontifícia Universidade Católica do Rio de Janeiro (PUC-Rio) e Universidade Católica de Petrópolis (UCP) - sob a liderança da Universidade do Estado do Rio de Janeiro (UERJ).
} 
(BIOgraph), permitiu aglutinar um número mais significativo de pesquisadores, incorporar novas perspectivas de análises e, deste modo, ter um conjunto mais significativo de publicações, com as conferências, mesas redondas e simpósios.

Com relação aos eixos temáticos, as ênfases podem ser assim compreendidas, conforme sistematizado na carta aos quase 1000 congressistas, como aparece na programação do Vl:

O eixo Pesquisa (Auto)Biográfica, Fontes e Questões, com diferentes nomenclaturas, esteve presente como temática no I, III, V CIPAs: Relação pesquisador/pesquisado na pesquisa (auto)biográfica (I CIPA), Pesquisa (auto)biográfica: fundamentos e metodologia (I CIPA) e Dimensões epistemológicas e metodológicas da pesquisa (auto)biográfica (III e $\mathrm{V}$ (IPA). Nesse sentido, observamos a preocupação do campo na tematização das questões teórico-metodológicas, tendo no VI CIPA especial preocupação com a discussão das fontes da pesquisa (auto)biográfica, suas potencialidades e desafios. Por um lado, o desenvolvimento da abordagem e sua diversificação indica grande potencialidade na constituição instituinte de um caminho políticoepistêmico, por outra demanda o permanente exercício de reflexividade crítica, no sentido de não perder a inventividade que caracteriza a produção do campo, especialmente a brasileira, mas caminhando também no sentido do aprofundamento e consolidação dos trabalhos realizados. (BRAGANÇA e BALASSIANO, 2014, p. 12-13)

As discussões construídas sobre questões epistemológicas e teóricometodológicas têm possibilitado a ampliação de princípios sobre os estudos (auto)biográficos, ao aprofundar disposições sobre abordagens e fontes que têm sido utilizadas tanto em pesquisas no campo educacional, quanto diversas práticas de formação vinculadas à formação inicial e continuada, como também por meio da publicação de livros $^{7}$ que subsidiam os estudiosos, no que se refere aos diversos modos

\footnotetext{
7 Cabe aqui destacar a publicação da Série Clássicos das Histórias de Vida, no âmbito da Coleção Pesquisa (Auto)biográfica \& Educação, dirigidas por Maria da Conceição Passeggi, Elizeu Clementino de Souza e Christine Delory-Momberger, com a publicação dos seguintes títulos: NÓVOA, António e FINGUER, Matias. O método (auto)biográfico e a formação (2010); BERTAUX, Daniel. Narrativas de vida: a pesquisa e seus métodos (2010); JOSSO, Marie-Christine. Experiências de vida e formação (2010); PINEAU, Gaston e LE GRAND, Jean-Louis. As histórias de vida (2012); DELORY-MOMBERGER, Christine. As histórias de vida: da invenção de si ao projeto de formação (2014); FERRARROTTI, Franco. História e histórias de vida: o método biográfico nas Ciências Sociais (2014).
} 
de apropriação dos métodos e técnicas em contextos de pesquisa-ação-formação experiencial.

O eixo Espaços Formativos, Memórias e Narrativas trata de questões relacionadas às práticas de formação em diálogo com dispositivos situados em diversos espaços sociais. As discussões construídas neste eixo dialogam com o movimento das histórias de vida em formação, na medida em que partem das interfaces entre educação de adultos e o papel exercido pelas histórias de vida nos países francófonos, como férteis para a reinserção social dos sujeitos. Como sistematizado na carta-convite aos congressistas, destacamos questões vinculadas ao crescente número de trabalhos e expansão desse eixo nas diferentes edições do congresso, visto que:

O crescimento diversificado da abordagem, que observamos nos últimos anos, favoreceu a presença da perspectiva (auto)biográfica nos mais diversos campos da pesquisa educacional e, apesar dos diversos desdobramentos temáticos e teórico-metodológicos, é possível afirmar a significativa presença das relações entre investigação e formação. Nesse sentido, recebendo sempre significativo número de trabalhos, a dimensão formativa se fez presente em todos os CIPAs, tendo eixos com diferentes nomenclaturas como: Histórias de vida e de trabalho de professores (I CIPA), Histórias de vida, narrativas conhecimento de si, representações da docência (I CIPA), As artes e a invenção de si: questões de escrita e formação (II CIPA), As construções (auto)biográficas e as práticas de formação (II CIPA), (Auto)biografia e práticas de formação: lugares de aprendizagem e (re)invenção de si (III), Práticas de formação e pesquisas (auto)biográficas (IV CIPA) e Práticas de formação e pesquisas (auto)biográficas (V CIPA). (BRAGANÇA e BALASSIANO, 2014, p. 13)

O terceiro eixo do VI CIPA, ao propor um tema pulsante e emergente, centrou-se nas discussões sobre Narrativas digitais, memória e guarda, ao tratar de temáticas contemporâneas sobre outras formas de escritas, especialmente, as inscritas nos espaços virtuais e que possibilitam novas e distintas formas de sociabilidade do eu. Tal temática, ao apresentar-se pela primeira vez como eixo do congresso, não desconsidera estudos que já vêm sendo realizados no campo da pesquisa (auto)biográfica, ao discutir aspectos diversos sobre narrativas na web, expressas através de diferentes dispositivos, tais como: vídeos, imagens, textos e sons, como gêneros confessionais que se materializam nos espaços virtuais através da internet, expressando fecundas escritas de si, 
perfomatividade e idealização do eu, num jogo dialético entre esferas públicas e privadas da vida cotidiana, bem como questões vinculadas aos modos de produção, circulação, recepção e guarda das narrativas digitais ou webnarrativas, como férteis para o campo dos estudos (auto)biográficos.

Como aconteceu nos três últimos CIPAS, a infância ocupou uma das centralidades na sexta edição, através do eixo Infância, Aprendizagem e Exercício da Escrita, debruçando-se nas diferentes formas de escrita das crianças, com especial atenção para a compreensão da criança como sujeito de direitos, a escrita infantil e suas relações com a história e sociologia da infância, bem como a variedade de análises implicadas com os estudos e debates sobre a história da infância, a história da cultura escrita e também a história da educação, com atenção para a construção da escrita infantil e da autoria da criança, como uma das potências das narrativas no âmbito do VI CIPA.

A ampliação das discussões sobre (Auto)Biografia, Literatura e História tem sido uma das vertentes de diferente edições do congresso, que se materializa no eixo (Auto)Biografia, Literatura e História. Diferente das edições anteriores, o presente eixo buscou centrar atenção na tematização de questões relacionadas aos dilemas, políticas e modos de preservação e, também, sobre o descarte de documentos pessoais, com atenção para os aspectos concernentes à guarda e preservação dos documentos.

O eixo Escrita de Si, Resistência e Empoderamento configurou-se como uma temática inovadora, ao tomar como referência os trabalhos apresentados no Colóquio Internacional Vivre-Survivre. Récits de Résistance, o qual foi organizado pela Associação Internacional das Histórias de Vida em Formação e da Pesquisa Biográfica em Educação (ASIHVIF-RBE), possibilitando a publicação do livro Vivre-Survivre. Récits de Résistance (DELORY-MOMBERGER e NIEWIADOMSKI, 2009). O quantitativo de trabalhos vinculados ao eixo atestou a emergência de uma temática singular, que oportunizou discussões sobre escritas de si, resistência, empoderamento implicadas nas narrativas de sujeitos marginalizados, refugiados, excluídos e que vivem em situações-limites e muitas vezes à margem das sociedades contemporâneas, mas que, sobremaneira, constroem, através de suas narrativas, modos diversos de enfrentamento, de resistência e de recolocarem-se no mundo de forma empoderada. 
O último eixo - Histórias de Vida, Gênero e Educação destaca-se como segunda temática com maior quantidade de trabalhos apresentados, com enfoques sobre a temática (inter)geracional, cuja questão de gênero ganha relevo em diálogo com as produções do III, IV, V CIPAs, possibilitando reflexões sobre representações entre os gêneros, imagens e trajetórias pessoais e coletivas de sujeitos silenciados pela história.

As discussões empreendidas e a ampliação das redes de pesquisa favorecidas com a realização da sexta edição do CIPA, resultou em um espaço fecundo de intercâmbios acadêmicos e científicos entre pesquisadores do campo educacional brasileiro, em diálogo com pesquisadores estrangeiros e de outras áreas do conhecimento, o que se materializou na significativa e densa programação, contribuindo para o fortalecimento e visibilidade de questões emergentes sobre o (auto)biográfico no contexto político e cultural do país, bem como para a ampliação da rede e do movimento biográfico que tem se desenvolvido no Brasil.

O VI CIPA contou com um total de novecentos e dois (902) trabalhos inscritos e oitocentos e oitenta e oito (888) aprovados, assim distribuídos: 1. Pesquisa (Auto)Biográfica, Fontes e Questões (89); 2. Espaços Formativos, Memórias e Narrativas (515); 3. Narrativas Digitais, Memórias e Guarda (30); 4. Infância, Aprendizagem e Exercício da Escrita (39); 5. (Auto)Biografia, Literatura e História (59); 6. Escrita de Si, Resistência e Empoderamento (77) e 7. Histórias de Vida, Gênero e Educação (93). ${ }^{8}$

O quantitativo de trabalhos por eixo aponta para uma multiplicidade de lugares em que a pesquisa autobiográfica vem se constituindo, sugerindo que o VI CIPA favoreceu o debate com/sobre múltiplos olhares favorecidos pela pesquisa (auto)biográfica, contribuindo significativamente para a ampliação de redes de pesquisas, para a sistematização de estudos no campo da pesquisa (auto)biográfica vinculados às diferentes temáticas, subsidiando diálogos fecundos entre pesquisadores, estudantes de doutorado, mestrado, iniciação científica e de professores da educação básica.

Tais como explicitam os objetivos do congresso, as ações desenvolvidas, através da programação acadêmica e cultural, possibilitaram diálogos entre redes nacionais e internacionais de pesquisa (auto)biográfica, implicando nas discussões sobre as

8 Dados obtidos e sistematizados a partir do Sistema de Informação e de inscrições do VI CIPA. 
potencialidades das fontes (auto)biográficas em articulação com disposições políticas, simbólica, histórica, estética e ética na vertente da pesquisa-formação, bem como contribuindo para as múltiplas interfaces interdisciplinares do campo dos estudos (auto)biográficos, favorecendo aprofundamentos de temáticas, métodos, fontes e perspectivas de análises sobre as narrativas (auto)biográficas.

Os eixos, tais como explicitados na programação do congresso, permitiram-nos apreender e agrupar entradas temáticas que vêm se consolidando nas diferentes edições do congresso, especialmente, no que se refere às 'práticas de formação', aos estudos sobre 'memória e dimensões sócio-históricas', aos 'processos identitários', às 'dimensões teóricas e metodológicas da pesquisa (auto)biográfica', às discussões sobre 'corpos, saúde e cuidados de si', 'gênero, geração, interculturalidade' e também outras entradas na vertente que tratam do 'saber coletivo/resistências sociais'. Ainda assim, dadas as especificadas questões contemporâneas que transversalizam as biografias na sociedade brasileira, notadamente sobre os debates inscritos entre o público e o privado que envolveram a produção, autorização e publicação de biografias, sentimos a plena necessidade de elegermos novas temáticas, constituindo novos eixos para esta edição, os quais se dedicaram às discussões sobre infância e exercício da escrita, narrativas digitais e, por fim, (auto)biografias, resistências e empoderamento.

\section{Coleção Modos de viver, narrar e guardar: algumas reflexões teórico- metodológicas}

Os temas escolhidos para a Coleção Modos de viver, narrar e guardar dão continuidade às reflexões sobre questões essenciais da investigação, tais como as dimensões epistemológicas, metodológicas e a análise de fontes; memórias, narrativas, práticas e espaços formativos; as relações entre autobiografia, literatura e história abrem espaços para novas reflexões sobre narrativas digitais e guarda, resistência e empoderamento, como temáticas que se relacionam às questões contemporâneas implicadas com as biografias e (auto)biografias.

As discussões sobre (auto)biografias, fontes e questões teórico-metodológicas foram tematizadas no livro Pesquisa (auto) biográfica, fontes e questões, contribuindo 
fortemente para as discussões epistemológicas e metodológicas sobre o campo da pesquisa (auto)biográfica. Como expressa na apresentação do livro e através da forma de organização em duas partes que dialogam entre si, a primeira que tematiza sobre dimensões epistemológicas, metodológicas e a análise das fontes e a segunda que aborda trajetórias e desafios das práticas, referenciais e fontes de pesquisa (auto)biográficas, evidenciando férteis construções teóricas sobre fontes e questões metodológicas, tal como aparece na apresentação do livro:

O presente livro que labora com o tema Pesquisa (Auto)Biográfica, Fontes e Questões nos leva a rever o itinerário percorrido, potencialidades e fragilidades das bases nas quais fundamentamos nossas práticas de pesquisa e formação, bem como as perspectivas instituintes que se abrem ao campo. Essa é a preocupação que une os textos reunidos no presente livro. [...]

Os capítulos que compõem o conjunto das narrativas do presente livro apresentam, como não poderia deixar de ser, uma preocupação que as aglutina em uma unidade na diversidade: a reflexão sobre a potência das fontes em pesquisa (auto)biográfica e, por essa razão, buscam, como anunciamos no início do presente texto, a itinerância, ou seja, as trilhas percorridas, alguns indícios e sinais, marcas que já se fazem presentes na produção acadêmica do campo educacional, nas práticas de pesquisa e formação e, especialmente, na trajetória formativa de estudantes, professores e pesquisadores. Os diferentes capítulos nos mobilizam, pois, em face das questões tratadas, caras para nós, o que não elide a possibilidade de o leitor interagir com as narrativas deste livro para além dessas questões dada a riqueza que caracteriza as fontes (auto)biográficas. (ABRAHÃO; BRAGANÇA;ARAÚJO, 2014, p. 16, p. 23)

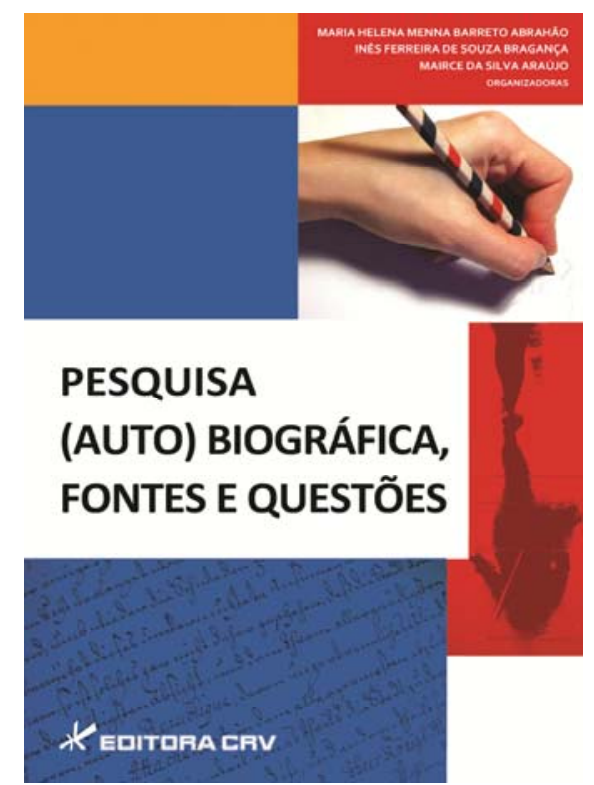


O tema da formação tem se configurado, em diferentes edições do congresso, como potente, na medida em que tem acolhido uma diversidade de trabalhos que no campo da formação de professores ocupa lugar de destaque, na medida em que sistematizam aspectos concernentes às práticas de formação inicial, continuada, às práticas de formação e aos processos de acompanhamento e mediação biográficas relacionados às escritas de si na área educacional e sobremaneira nas experiências diversas de formação de professores. Tais abordagens aparecem no livro 'Espaços formativos, memórias e narrativas', o qual amplia discussões anteriores que aconteceram nas diferentes edições dos CIPAs, como o eixo temático que tem acolhido a maior quantidade de trabalhos.

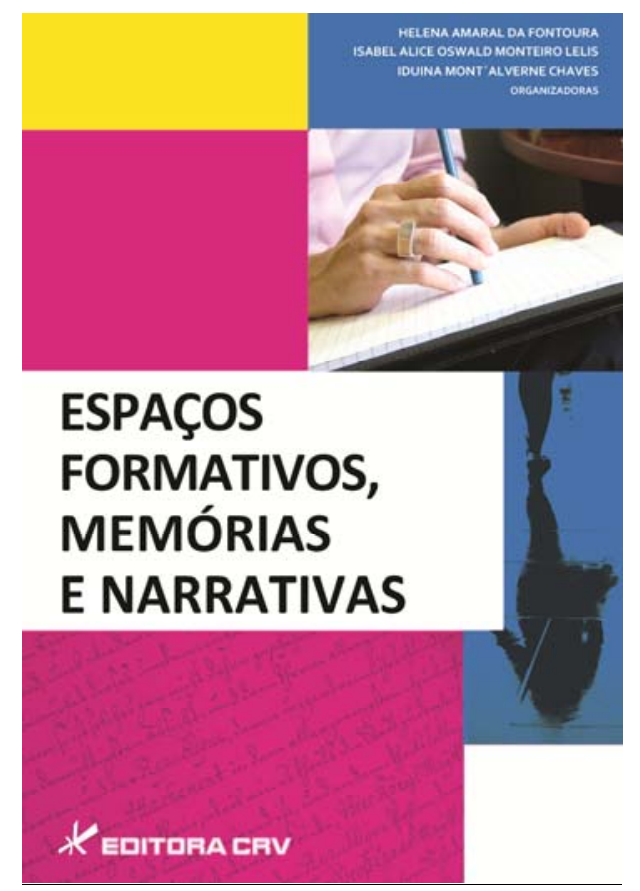

As práticas de formação são tematizadas no livro, tal como aparece na apresentação do mesmo, articulando:

[...] um conjunto de trabalhos de pesquisadores que vem recorrendo a histórias de vida e a métodos autobiográficos para a compreensão do trabalho e da formação de professores, trazendo experiências que buscam refletir sobre a fecundidade da memória e das trajetórias de vida nos processos de socialização familiar, escolar, profissional vividos pelos sujeitos sociais, com impacto nas disposições para a docência. 
Sob variados recortes temáticos e opções teórico-epistemológicas, vamos sendo apresentados/as a pesquisas, relatos de experiência e movimentos educacionais, desenvolvidos nos últimos anos, no Brasil, em Portugal, na Espanha, na Argentina, na Colômbia e na Itália, compondo um amplo quadro nacional e internacional. Ampliar pesquisas em rede a partir de diálogos entre pesquisadores ultrapassa fronteiras e traz significativos ganhos para o campo dos estudos (auto)biográficos, tanto do ponto de vista da solidez teórica como da originalidade dos objetos de pesquisa. Seja sob a perspectiva da construção da memória pedagógica, das lembranças da escola e de seus agentes, seja sob a forma da potencialidade da história de vida nos processos de formação dos professores, o que deve ser destacado é que, a partir dos anos 90, assistimos à busca por novas abordagens, novas fontes no sentido de enriquecer a investigação científica e os processos de formação de indivíduos e grupos sociais. [...] (FONTOURA;LELIS; CHAVES, 2014, p. 1622)

A infância é um dos temas que, anteriormente, aparecia ao lado de outros, como em 2012, junto de geração, juventude e família, para sublinhar a perspectiva geracional das investigações (auto)biográficas. Na apresentação, as organizadoras de Infância, aprendizagem e exercício da escrita destacam e justificam a especificidade do novo recorte temático, afirmando que "a partir de enfoques distintos, em diálogos com a produção acadêmica de diversas tradições disciplinares, os autores apontam caminhos possíveis de investigações sobre e com as crianças no contexto escolar", o que se expressa na arquitetura do livro dividido em três partes:

A primeira reúne estudos de abordagem histórica que privilegiam as escritas produzidas pelas crianças na escola ou escritas livres que não escapam das prescrições e recomendações das professoras. Variados suportes, cartas, cadernos e jornais produzidos por crianças, são aqui estudados como veículos para o exercício de práticas de escritas de si e constituem o alvo das atenções. Os autores buscam rastros de subjetividade, desejos, expectativas, em meio às páginas e se defrontam com descrições variadas sobre modelos de escola, concepções de ensino, representações de época. [...] A segunda vertente privilegia as pesquisas com crianças. [...] Os estudos colocam em discussão a palavra das crianças como fonte de pesquisa, priorizando tanto a oralidade quanto a linguagem escrita sob a forma de pequenas mensagens e de desenhos. Ao abordar o modo como elas concebem, narrativamente, a escola e os ambientes que as acolhem, põem em relevo as necessárias rupturas e a legitimação da criança e de suas narrativas nas pesquisas educacionais, apontando desdobramentos relacionados ao quadro teóricometodológico e da ética na pesquisa. [...] A terceira e última vertente 
discute o papel de educadores que se dedicaram à educação das crianças e, através de sua prática pedagógica e produção escrita, elaboraram registros da infância e sobre a infância e trouxeram a criança para o centro da ação educativa. (MIGNOT; SAMPAIO;PASSEGGI, 2014, p. 15-16)

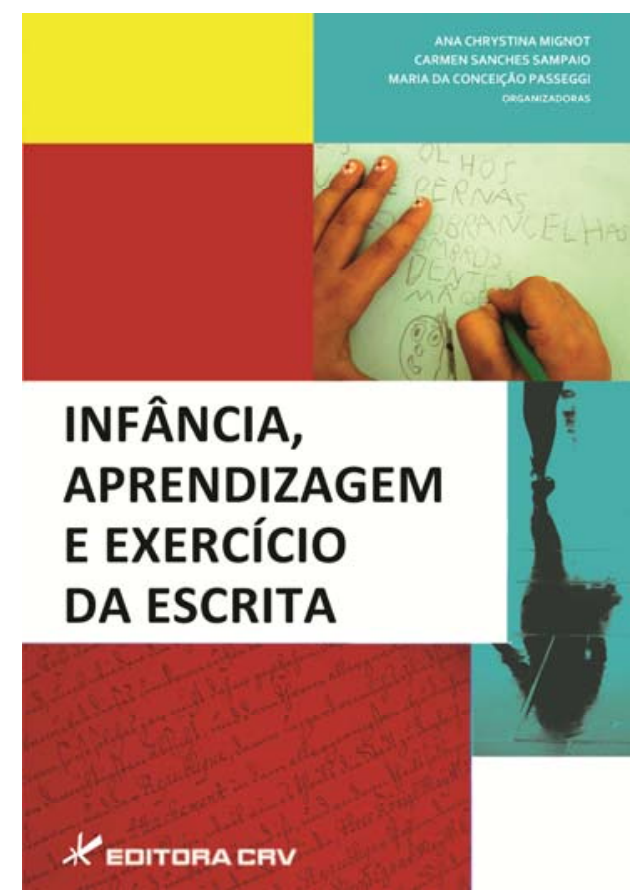

As relações entre autobiografia, literatura e história já tiveram como desdobramentos o cinema e a fotografia, no CIPA de 2010; agora, estes temas acentuam, por exemplo, as escritas de diários, as percepções de si e da escola em obras literárias memorialísticas, em coleção de cartas, em textos póstumos, bem como discutem processos de construção de narrativas (auto)biográficas. Na apresentação do livro, as autoras destacaram as preocupações que inspiraram a reunião dos textos:

A presente coletânea reúne textos que têm como temática principal as relações entre (auto)biografia e a escrita da história, considerando tanto as fronteiras como as aproximações com a literatura e a educação e, ainda, os dilemas éticos que envolvem o ato de biografar e as políticas públicas destinadas à preservação da memória das pessoas comuns, em contraposição à tendência de espetacularizar a vida daqueles que em algum momento se destacaram dos demais.

No sentido de compor uma obra tão complexa, são autores nessa coletânea pesquisadores da literatura, história e educação, tendo como foco comum a produção biográfica em seus entrelaçamentos com essas 
três áreas, delineando a metáfora que intitula o livro: "papéis guardados" e revisitados em nossos escritos. A imagem do título reflete, em muitos aspectos, o momento em que se encontram e se articulam sob um fio condutor, as histórias de vida, de mulheres nobres, escravos, intelectuais e professores, em tempos e contextos diferenciados. Sua leitura possibilita entrever intimidades registradas em egodocumentos e escritos (auto)biográficos, que aguçam, não só a nossa curiosidade sobre o objeto investigado, mas sobre a metodologia que permitiu a recomposição de vidas e de narrativas marcadas pela construção coletiva entre personagens e narradores/escritores/biógrafos, ainda que, às vezes, separados por intensos limites temporais e geográficos. (VASCONCELOS; CORDEIRO; VICENTINI, 2014, p. 15)

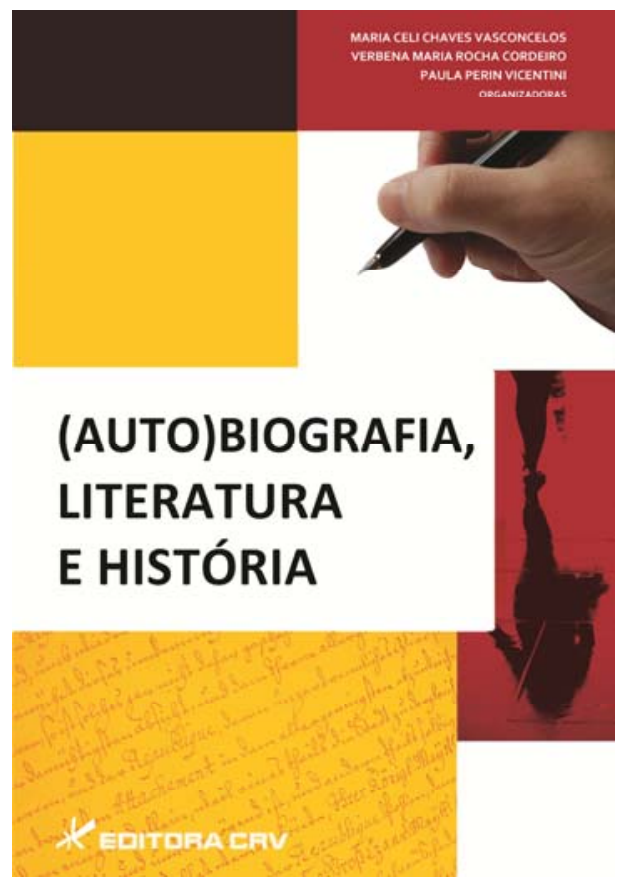

Uma inclusão auspiciosa nesta coleção de 2014 é a das Narrativas digitais, memórias e guarda, temas que, embora não constituam inteira novidade no campo, ainda não tinham tido o merecido destaque nas coletâneas anteriores. Na Internet criam-se blogs de todo tipo, redes sociais, museus digitais, videobiografias, sites de narrativas autobiográficas, etc., que são acessados por meio de vários dispositivos móveis. O íntimo, que se torna público, um público bem alargado que não conhece distâncias geográficas, pode ser algo contagiante. As narrativas de si, estimuladas pela Web, produzem novas modalidades de escritores e de leitores, implicando em outras e novas formas contemporâneas de escritas de si. Apesar dos poucos trabalhos apresentados no evento sobre a temática, quando comparados a outros, pode-se afirmar que é um tema 
emergente que vem arrebatando a atenção de pós-graduandos. A seleção de textos feita pelos organizadores do livro permitiu ressaltar especificidades das escritas na internet que sugerem a importância de aprofundamento de estudos:

Gostaríamos de ressaltar duas especificidades da escrita na internet que apareceram nos artigos deste livro, que dizem respeito aos processos comunicacionais síncronos e assíncronos. A expectativa de resposta do primeiro é imediata, e se assemelha às interações face a face, conforme fica evidente nas experiências de internautas em salas de bate-papo e nas interações online realizadas nos chats de redes sociais (RECUERO, 2009). Por outro lado, a comunicação mediada por computador assíncrona não apresenta expectativa de resposta imediata, como é o caso das trocas de e-mails e das postagens compartilhadas nos sites de redes digitais (id, ibid). Neste sentido, os processos síncronos e assíncronos permitem que os ambientes virtuais se constituam como importantes interfaces comunicacionais, propiciando que o diálogo entre os internautas seja dinâmico, participativo e que as múltiplas vozes dos sujeitos se entrecruzem e teçam saberes colaborativamente. [...]

Esperamos, a partir dessas palavras introdutórias, ter suscitado o interesse e a curiosidade do leitor para imergir nos artigos que apresentamos a seguir. Com diferentes focos e apoiando-se em vertentes teórico-metodológicas diversas, tais artigos têm em comum abordar o importante tema das narrativas (auto)biográficas na Web, trazendo as potencialidades e desafios desses novos gêneros confessionais da internet, bem como explorando as transformações na produção dos modos de estar, registrar e guardar na contemporaneidade. (OSWALD; COUTO JUNIOR; WORCMAN, 2014, p. 1617)

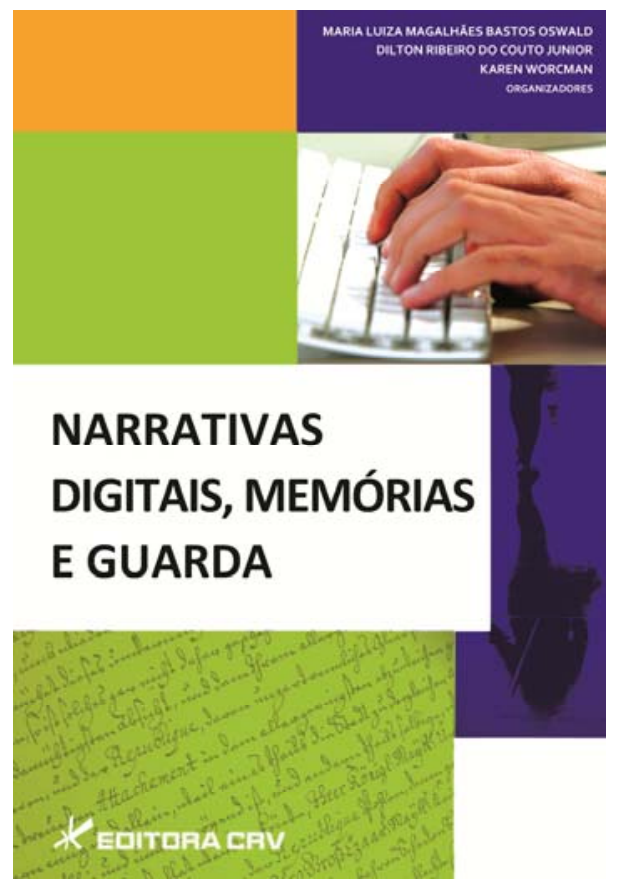


Outra inclusão relevante atestando nossas convergências diz respeito aos temas da resistência, empoderamento e construção de si, em narrativas de homens, mulheres, crianças e jovens, que experimentaram todo tipo de dificuldades, que marcaram profundamente suas vidas. Esta inclusão inspirou-se em um evento promovido pela ASIHVIF-RBE, em 2009, sobre "viver, sobreviver e resistir" (DELORY-MOMBERGER; NIEWIADOMSKI, 2009), no qual as narrativas dos sujeitos tornaram-se espaços de resistência e reconstituição de suas identidades. As questões examinadas referem-se a guerras, holocausto, ditadura, imigração, emigração, doenças, construção de imagens sobre juventude e infância marginalizadas, além de análises sobre outras formas de violência, resistência e empoderamento, como se pode ver na apresentação da obra:

O livro Escritas de si, resistência e empoderamento discute questões relacionadas à pesquisa (auto)biográfica e, em particular, sobre as escritas de si como forma de resistência e de empoderamento, reunindo pesquisadores brasileiros, franceses e portugueses de diferentes centros de pesquisa que se debruçam sobre a temática da pesquisa (auto)biográfica e suas vinculações com as narrativas de guerra, processos de migração, análise de impressos e de imagens, na vertente das práticas de resistência e empoderamento do sujeito que narra. [...] Nesse sentido, a presente publicação representa parte de um processo de constituição de um campo de estudo e pesquisa que reconhece estes relatos de si como lugares de uma ação em que narrar é também afirmar sobre a existência e resistir. As "feridas" secretas não precisam mais ser guardadas e negadas, passam a ser explicitadas e (re)organizadas no mundo que nos cerca. Em outras palavras, trata-se de um lugar de empoderamento.

A presente publicação trabalha, então, neste universo plural, diverso e singular, no qual cada texto desvela olhares singulares e específicos de narrativas de resistência e empoderamento, através das implicações com os lugares e os modos diversos como os sujeitos vivenciaram e guardam marcas das "feridas" da vida ou como constroem, através da escrita de si, formas de enfrentamento de traumas e de resistências nas aprendizagens biográficas da vida. [...]

Pesquisa (auto)biográfica, resistência e empoderamento configuram a ideia central da presente obra, na medida em que compreende a escrita como espaço-tempo de poder-saber e como forma de ordenar o mundo, de atribuir-lhe sentido, de divulgar uma visão autorizada de si e do outro. As narrativas de resistência ao materializarem, através das escritas conscientes e/ou secretas, negadas, censuradas e ou públicas, transformam-se em ferramentas de conscientização, de elaboração de uma visão contra hegemônica do mundo. A escrita de si, como singularplural, permite ao sujeito, em processo de reflexividade biográfica, criar disposições e modos de resistir, de agir frente aos acontecimentos vividos, ressignificando-os através da escrita. [...] 
Escritas de si, resistência e empoderamento, configuram-se como ideias centrais da presente obra, tendo em vista o lugar que ocupam as narrativas de si como um modo de resistência, de empoderamento, ao abrir espaços para a deflagração e publicização de temas e experiências que quando negadas, caladas, silenciadas situam os indivíduos que experimentaram os horrores e as mazelas da existência humana num (des)lugar. (SOUZA; BALASSIANO; OLIVEIRA, 2014, p. 13-15-23)

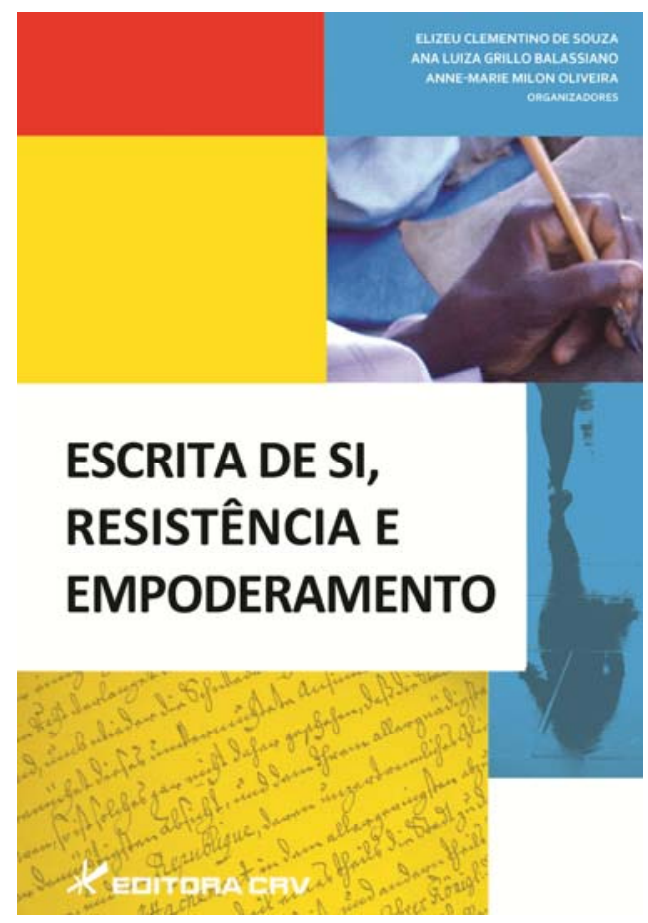

Histórias de vida, gênero e educação é o livro que encerra a coleção. As questões trabalhadas fazem emergir mulheres em diferentes espaços e situações de vida escolar e acadêmica; em vários tipos de instituições de formação; em trajetórias profissionais, desveladas em relatos orais, memórias, canções, histórias orais e documentos, sintetizado assim por suas organizadoras:

[...] os trabalhos que compõem este livro privilegiam o campo do conhecimento que aborda as relações entre Gênero e Educação, tendo em vista a construção histórico-cultural do ser masculino e feminino, através das diferentes formas de educar homens e mulheres. Desvelam, portanto, limites e encontros do viver/sentir, presentes em história e memórias individuais e coletivas de diferentes gerações.

Pode-se observar, ainda, que os estudos buscaram aproximações, rupturas e permanências nas marcas circulantes nos espaços público e 
privado, investigando pegadas e vestígios das subjetividades masculinas e femininas, daqueles (as) personagens investigados (as). Trata-se, então, de pesquisas biográficas que percorrem histórias de vidas e discursos, principalmente femininos, nos permitindo analisar diferentes identidades femininas. Nesse sentido, as Histórias de Vida, Gênero e Educação, nomeiam o presente livro, e colocam em destaque a importância de privilegiar o conceito de gênero enquanto categoria histórica, associando tais estudos ao campo da historiografia e em particular, aos estudos (auto) biográficos. (FARIA; LOBO; COELHO, 2014, p. 17-18)

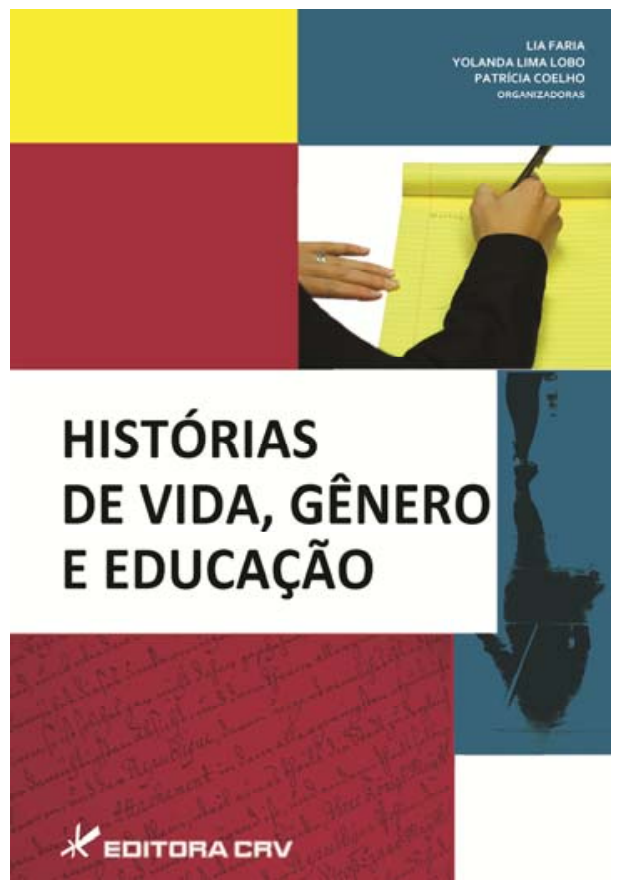

As interfaces interdisciplinares, especialmente através de diálogos com grandes áreas de conhecimento - Educação, História, Literatura, Filosofia, Sociologia, Psicologia e Antropologia - que têm se debruçado sobre os estudos e/ou práticas de formação no campo (auto)biográfico têm favorecido ampliações de redes de pesquisa-formação, notadamente, pelas ações de cooperação acadêmica empreendidas entre associações de pesquisa da América Latina, Europa e América do Norte, demarcando avanços, modos próprios de trabalho e singularidades como as redes, as associações e os seus pesquisadores vêm constituindo um movimento internacional no domínio dos estudos (auto)biográficos. 
A coleção Modos de viver, narrar e guardar, ao verticalizar os eixos temáticos do congresso, aprofunda aspectos epistemológicos e teórico-metodológicos, relacionados à pluralidade de formas de trabalho, às múltiplas temporalidades e aos diversos espaços biográficos e autobiográficos que se inscrevem na existência humana. Os diferentes modos de narrar sejam do adulto, do jovem e da criança, que ao contarem e partilharem suas experiências de vida-formação em espaço de formação e/ou com vinculação as pesquisas, têm nas histórias singulares e coletivas formas distintas de explicitarem marcas da memória, dos projetos existenciais, das práticas de formação e de inserção social-profissional que contribuem para o alargamento dos estudos (auto)biográficos, os quais são tematizados na presente coleção, aqui brevemente analisada.

\section{Algumas conclusões}

Os sete livros que integram a Coleção Modos de viver, narrar e guardar, com 119 capítulos, socializam, assim, aproximações e distanciamentos dos modos próprios como os pesquisadores têm se debruçado sobre o (auto)biográfico, envolvendo reflexões e partilhas de pesquisas desenvolvidas por estudiosos do campo do Brasil, Argentina, Colômbia, México, Espanha, Bélgica, Chile, Peru, Itália, Portugal e França, revelando questões epistemológicas, metodológicas e de práticas de formação sobre as pesquisas que se apropriam do amplo e intenso universo de fontes biográficas e autobiográficas, para apreender modos de viver e de narrar com ênfase em aspectos sobre narrativas infantis, narrativas digitais, diferentes modos de escritas e suas relações com as práticas de resistência e empoderamento, implicando revisitar formas diversas de preservação da memória, do guardar as experiências individuais, coletivas e institucionais dos sujeitos.

Os olhares e interpretações se entrecruzam em torno de diferentes sujeitos professores, alunos, pais, doentes, crianças, jovens, adultos, velhos, encarcerados, mulheres, gays, negros, índios, escritores, poetas -, em variados espaços: escolas, casas, hospitais, abrigos, presídios, aldeias, ruas, e cidades, o que permite uma instigante aproximação com memórias minimizadas, marginalizadas, negadas, silenciadas ou esquecidas. Nestas páginas estão as histórias e as vidas que são narradas oralmente por aqueles que não dominam a escrita, bem como um conjunto significativo de interpretações que atraem o leitor para outros suportes de escrita (auto)biográfica além 
do papel, na medida em que as escritas de si invadem cada vez mais as telas dos novos equipamentos tecnológicos convidando a invadir intimidades alheias.

Os livros que integram a presente coleção contribuem, significativamente, para o aprofundamento de questões epistemológicas e teórico-metodológicas da pesquisa (auto)biográfica e seus limites, na medida em que revelam diálogos entre diversos sujeitos que, ao partilharem suas trajetórias de investigação, permitem surpreender singulares modos de viver, narrar e guardar.

Inicialmente trabalhadas na Antropologia, Sociologia e História, como metodologia de pesquisa na problematização e registro de tramas sociais e históricas, as narrativas chegaram à educação na interface entre investigação e formação. Pineau (2006) destaca três períodos do movimento das histórias de vida: nos anos 1980 a eclosão, nos anos 1990 a fundação e, a partir dos anos 2000, o desenvolvimento diferenciado. No Brasil, é possível notar um fértil desdobramento da referida abordagem em caminhos teórico-metodológicos que valorizam a narrativa reflexiva, as práticas de formação e modos diversos como pesquisadores e grupos de pesquisas têm se debruçado e desenvolvido estudos no campo da pesquisa (auto)biográfica. A realização das seis edições dos Congressos Internacionais sobre Pesquisa (Auto)biográfica, tem contribuído para consolidação do campo e visibilidade de uma vasta produção na área. Ressalta-se, ainda, a fundação, em 2008, da Associação Brasileira de Pesquisa (Auto)Biográfica (BIOgraph) como um marco nesse caminho e da constituição do campo brasileiro em diálogo com movimentos internacionais. 


\section{Referências}

ABRAHÃO, Maria Helena Menna Barreto Abrahão; BRAGANÇA, Inês Ferreira de Souza; ARAÚJO, Mairce da Silva. Pesquisa (auto) biográfica, fontes e questões. Curitiba: CRV, 2014. (Coleção Modos de Viver, narrar e guardar, v. 1)

BERTAUX, Daniel. Narrativas de vida: a pesquisa e seus métodos. Tradução de Zuleide Cardoso Cavalcanti, Denise Maria Gurgel Lavallée, Natal: EDUFRN; São Paulo: Paulus, 2010.

BRAGANÇA, Inês Ferreira de Souza e BALASSIANO, Ana Luiza Grillo. Carta-convite aos congressistas. In.: MIGNOT, Ana Chrystina e SOUZA, Elizeu Clementino de. Programa VI CIPA - Congresso Internacional de Pesquisa (Auto)biográfica - Entre o público e o privado: modos de viver, narrar e guardar. Rio de Janeiro: BIOgraph, 2014, p. 11-14.

DELORY-MOMBERGER, Christine et NIEWIADOMSKI , Christophe. Vivre-survivre. Récits de résistance. Paris: Téraèdre, 2009.

DELORY-MOMBERGER, Christine. As histórias de vida: da invenção de si ao projeto de formação. Tradução de Carlos Eduardo Galvão Braga e Maria da Conceição Passeggi, Natal: EDUFRN; Salvador: EDUNEB; Porto Alegre: EdPUCRS, 2014.

FARIA, Lia; LOBO, Yolanda Lima; COELHO, Patrícia. Histórias de vida, gênero e educação. Curitiba: CRV, 2014. (Coleção Modos de Viver, narrar e guardar, v. 7)

FERRARROTTI, Franco. História e histórias de vida: o método biográfico nas Ciências Sociais. Tradução de Carlos Eduardo Galvão Braga, Maria da Conceição Passeggi, Natal: EDUFRN, 2014.

FONTOURA, Helena Amaral da; LELIS, Isabel Alice Oswald Monteiro; CHAVES, Iduina Mont'Alverne. Espaços formativos, memórias e narrativas. Curitiba: CRV, 2014. (Coleção Modos de Viver, narrar e guardar, V. 2)

JOSSO, Marie-Chrystine. Experiências de vida e formação. Tradução José Cláudio, Júlia Ferreira; 2.ed., Natal EDUFRBN; São Paulo: Paulus, 2010.

MIGNOT, Ana Chrystina; SAMPAIO, Carmen Sanches; PASSEGGI, Maria da Conceição. Infância, aprendizagem e exercício da escrita. Curitiba: CRV, 2014. (Coleção Modos de Viver, narrar e guardar, v. 4).

NÓVOA, António; FINGUER, Matias. O método (auto)biográfico e a formação. Tradução Maria Nóvoa, 2. ed., Natal, RN, EDUFRN, 2014.

OSWALD, Maria Luiza Magalhães Bastos; COUTO JUNIOR, Dilton Ribeiro do; WORCMAN, Karen. Narrativas digitais, memórias e guarda. Curitiba: CRV, 2014. (Coleção Modos de Viver, narrar e guardar, v. 3) 
PINEAU, Gaston e LE GRAND, Jean-Louis. As histórias de vida. Tradução de Carlos Eduardo Galvão Braga e Maria da Conceição Passeggi, Natal: EDUFRN, 2012.

PINEAU, Gaston. As histórias de vida em formação: gênese de uma corrente de pesquisaação-formação existencial. Educação e pesquisa, São Paulo, v. 32, n. 2, p. 329-343, maio/ago. 2006.

SOUZA, Elizeu Clementino de; BALASSIANO, Ana Luiza Grillo; OLIVEIRA, Anne-Marie Milon. Escrita de si, resistência e empoderamento. Curitiba: CRV, 2014. (Coleção Modos de Viver, narrar e guardar, v. 6)

SOUZA, Elizeu Clementino de; SOUSA, Cynthia Pereira de; CATANI, Denice Barbara. A pesquisa (auto)biográfica e a invenção de si no Brasil. Revista da FAEEBA - Educação e Contemporaneidade, Salvador, v. 17, n. 29, p. 1-11, jan./jun., 2008.

VASCONCELOS, Maria Celi Chaves; CORDEIRO, Verbena Maria Rocha; VICENTINI, Paula Perin. (Auto)biografia, literatura e história. Curitiba: CRV, 2014. (Coleção Modos de Viver, narrar e guardar, v. 5)

Universidade do Estado de Santa Catarina - UDESC 